\title{
The CCL5/CCR5 axis contributes to the perineural invasion of human salivary adenoid cystic carcinoma
}

\author{
ZHIYUAN SHEN $^{1 *}$, TIANYI LI ${ }^{2 *}$, DA CHEN $^{3 *}$, SEN JIA $^{1}$, XIANGMING YANG ${ }^{1}$, LIANG LIANG $^{1}$, \\ JUAN CHAI $^{1}$, XIAOBING CHENG ${ }^{1}$, XINJIE YANG ${ }^{1}$ and MOYI SUN ${ }^{1}$ \\ ${ }^{1}$ Department of Oral and Maxillofacial Surgery, School of Stomatology, The Fourth Military Medical University; \\ ${ }^{2}$ Department of Pediatric Dentistry, School of Stomatology, The Fourth Military Medical University; \\ ${ }^{3}$ Department of Oral Medicine, The Fourth Military Medical University, Xi'an, Shaanxi 710032, P.R. China
}

Received August 29, 2013; Accepted October 14, 2013

DOI: $10.3892 / o r .2013 .2920$

\begin{abstract}
Salivary adenoid cystic carcinoma (SACC) has a unique tendency for perineural invasion (PNI), which results in tumor recurrence and poor prognosis. Recent studies have shown that the chemokine CCL5 and its receptor CCR5 play important roles in tumor invasion and metastasis. However, the role of the CCL5/CCR5 axis in the PNI of SACC has not been studied to date. In the present study, we evaluated the expression of CCL5 and CCR5 in SACC cases and nerve tissues, and performed a series of in vitro assays with the SACC cell line, SACC-83, to indicate the role of the CCL5/CCR5 axis in the PNI of SACC. We found that CCL5 $(35.9 \% ; 23 / 64)$ and CCR5 $(70.3 \%$; 45/64) were positively expressed in SACC cases, and the expression of CCR5 was significantly associated with the PNI of SACC $(\mathrm{P}<0.05)$. We also found that SACC-83 cells expressed the functional receptor, CCR5, for the chemokine CCL5, as demonstrated by calcium mobilization and actin polymerization assays. Furthermore, we found that exogenous CCL5 significantly facilitated the migration, invasion and PNI activity of SACC- 83 cells in vitro $(\mathrm{P}<0.05)$. Further study showed that the CCR5 inhibitor (maraviroc) effectively blocked the migration, invasion and PNI activity of SACC-83 cells with or without CCL5 stimulation $(\mathrm{P}<0.05)$. These results indicate that the CCL5/CCR5 axis plays a critical role in the PNI of SACC, and that antagonists against CCR5 may be an effective anti-PNI agent for SACC therapy.
\end{abstract}

Correspondence to: Professor Moyi Sun or Dr Xinjie Yang, Department of Oral and Maxillofacial Surgery, School of Stomatology, The Fourth Military Medical University, 145 West Changle Road, Xi'an, Shaanxi 710032, P.R. China

E-mail: moyisun@163.com

E-mail: yangxinjie1983@gmail.com

${ }^{*}$ Contributed equally

Key words: salivary adenoid cystic carcinoma, perineural invasion, CCL5, CCR5

\section{Introduction}

Certain types of cancer have a special proclivity for perineural invasion (PNI), and these cancers are known as 'neurotropic cancers' (1). PNI is defined as the presence of tumor cells in the perinerium space of local peripheral nerves. Clinically, PNI has been recognized as a distinct route of tumor cell dissemination and is associated with the poor prognosis of these neurotropic cancers (1). Studies have found that PNI is more common than previously suspected and is associated with tumor recurrence and the poor prognosis of salivary adenoid cystic carcinoma (SACC) $(2,3)$, colon cancer (4), prostate cancer $(5,6)$, and pancreatic cancer $(7,8)$. Although a series of molecules has been found to play critical roles in the progression of PNI of neurotropic cancers, the molecular mechanisms of PNI have not yet been fully understood. Therefore, a better understanding of the molecular mechanisms of PNI would provide new strategies for the control of tumor dissemination in patients with neurotropic cancers.

Chemokines coupled with their receptors on cancer cells play important roles in tumor cell migration, invasion and metastasis (9-11). CCL5 is an inflammatory chemokine that is associated with the chemotactic activity of T cells, monocytes, dendritic cells, eosinophils and basophils (12). Previous studies have found that CCL5 is also secreted by Schwann and dorsal root ganglia cells (13). CCR5, as the chemokine receptor for CCL5, is predominantly expressed in tumor cells and is correlated with invasion and metastasis of various types of tumors $(14,15)$. Recent studies have found that exogenous CCL5 may significantly promote the migration and invasion of human breast cancer cells in vitro (16-18). Further studies showed that the CCR5 antagonist may obviously block the invasion and metastasis of breast cancer cells (19). These results suggest that the CCL5/CCR5 axis is associated with the invasion and dissemination of tumor cells. Interaction of tumor cells with nerves is currently recognized to have a fate-determining role in the progression and outcome of neurotropic cancers (20). However, whether the CCL5/CCR5 axis participates in tumor-nerve interaction and mediates the PNI of neurotropic cancers has not been previously reported.

SACC is a common neurotropic cancer and accounts for $\sim 20 \%$ of all salivary gland malignancies and $1 \%$ of all head 
and neck cancers (21). In the present study, we investigated the expression of the CCR5/CCL5 axis in SACC cases and its association with the PNI of SACC by immunohistochemistry assay. We further investigated the effect of the CCR5/CCL5 axis on the PNI activity of SACC cells by a series of in vitro assays using CCL5 stimulation and/or CCR5 blockage. Our results demonstrated for the first time that the CCL5/CCR5 axis may participate in the tumor-nerve interaction and may function in the progression of PNI of SACC.

\section{Materials and methods}

Tumor sample collection and processing. The present study was approved by the Ethics Committee of the Fourth Military Medical University, Xi'an, China. Written informed consent was provided by all patients. Sixty-four primary SACC samples and 30 normal human peripheral nerve tissues were collected from the School of Stomatology of the Fourth Military Medical University, Xi'an, China. All tissues were immediately fixed with $4 \%$ paraformaldehyde in PBS, embedded in paraffin and sectioned $(4-\mu \mathrm{m})$ for use. All SACC samples were pathologically diagnosed as SACC and evaluated by H\&E staining for conventional histological assessment.

Cell line and culture conditions. The human SACC cell line, SACC-83, was kindly provided by Dr Shenglin Li (Peking University, China). SACC-83 cells were cultured in RPMI-1640 (HyClone, USA) with $10 \%$ fetal bovine serum, 100 units $/ \mathrm{ml}$ penicillin and $0.1 \mathrm{mg} / \mathrm{ml}$ streptomycin, and were maintained in media at $37^{\circ} \mathrm{C}$ in a humid atmosphere of $5 \% \mathrm{CO}_{2} / 95 \%$ air.

Immunohistochemistry. To evaluate regional distribution and cellular expression of CCR5 and CCL5 in the clinical tissues, immunohistochemical staining was performed as previously described (22). Primary antibodies, polyclonal rabbit anti-human CCR5 (1:100) and polyclonal rabbit anti-human CCL5 (both from PeproTech, USA; 1:100), were used. Negative controls were performed by omitting the primary antibodies.

All immunostained sections were evaluated in a blinded manner by two pathologists (Yuan Liu and Jun Zhou). Results of the staining for CCR5 and CCL5 were classified into the following 3 categories: negative staining (-), $<25 \%$ of cells stained; moderate staining $(+), 25-50 \%$ of cells stained; and strong staining $(++),>50 \%$ of cells stained.

Immunofluorocytochemistry. Cells were cultured on 12-mm coverslips for $24 \mathrm{~h}$ at $37^{\circ} \mathrm{C}$ in a humid atmosphere of $5 \%$ $\mathrm{CO}_{2} / 95 \%$ air. Cells were then fixed with $4 \%$ paraformaldehyde for $15 \mathrm{~min}$ and permeabilized in $0.1 \%$ Triton X-100 for $10 \mathrm{~min}$. The cells were subsequently incubated with polyclonal rabbit anti-human CCR5 (1:100) or polyclonal rabbit anti-human CCL5 (1:100) overnight at $4^{\circ} \mathrm{C}$, and then incubated in goat anti-rabbit secondary antibody (PeproTech; 1:200) for $1 \mathrm{~h}$ at room temperature. After washing with PBS for 3 times, the cells were examined using a fluorescence microscope (Leica, Germany).

Analysis of CCR5 expression by flow cytometry. Harvested cells $\left(5 \times 10^{6}\right)$ were resuspended with $1 \%$ FCS-PBS and were incubated with anti-CCR5-FITC (1:100) or anti-CCL5-FITC (both from PeproTech; 1:100) in the dark at $37^{\circ} \mathrm{C}$ for $1 \mathrm{~h}$. Cells were then washed, centrifuged and resuspended in $500 \mu \mathrm{l} \mathrm{PBS}$. The fluorescence intensity was analyzed by a flow cytometer (BD Biosciences, USA).

Analysis of $\mathrm{Ca}^{2+}$ mobilization by flow cytometry. $\mathrm{Ca}^{2+}$ mobilization was performed with the fluorescent $\mathrm{Ca}^{2+}$ indicator Fluo-3 as reported (23). Harvested cells $\left(1 \times 10^{7}\right)$ were loaded with Fluo-3AM (5 $\mu \mathrm{M}$; Sigma, USA) in the dark at $37^{\circ} \mathrm{C}$ for $45 \mathrm{~min}$, and then washed 2 times with $1 \%$ FCS-PBS. Then, cells were diluted to $5 \times 10^{6}$ cells $/ \mathrm{ml}$ and kept in the dark at $37^{\circ} \mathrm{C}$ for $30 \mathrm{~min}$ before the beginning of the $\mathrm{Ca}^{2+}$ mobilization measurements. After adding $100 \mathrm{ng} / \mathrm{ml} \mathrm{CCL5,} \mathrm{the} \mathrm{fluores-}$ cence intensity of the cells was recorded by a flow cytometer. Maximal $\mathrm{Ca}^{2+}$ release was measured by lonomycin (Sigma) as previously reported (23). In the other group, cells were pretreated with $200 \mu \mathrm{g} / \mathrm{ml} \mathrm{maraviroc} \mathrm{for} 30 \mathrm{~min}$ at $37^{\circ} \mathrm{C}$ before CCL5 treatment.

Confocal microscopy for the actin polymerization assay. Cells were cultured on 12-mm coverslips for $6 \mathrm{~h}$, and incubated with $100 \mathrm{ng} / \mathrm{ml} \mathrm{CCL5}$ for $30 \mathrm{~min}$ at $37^{\circ} \mathrm{C}$. In the other group, cells were pretreated with $200 \mu \mathrm{g} / \mathrm{ml}$ maraviroc for $30 \mathrm{~min}$ at $37^{\circ} \mathrm{C}$ before CCL5 treatment. Cells were then fixed with $4 \%$ paraformaldehyde for $15 \mathrm{~min}$ and incubated with rhodamine-labeled phalloidin (Sigma) at $37^{\circ} \mathrm{C}$ for $30 \mathrm{~min}$. After washing with PBS for 3 times, cells were observed by confocal microscopy (Olympus Corporation, Japan). Negative controls were performed by incubating cells in serum-free RPMI-1640 without CCL5.

In vitro migration and invasion assays. Migration and invasion assays were performed using 12-mm-diameter inserts with a $8-\mu \mathrm{m}$ pore size in 24 -well dishes (Corning, USA). For the migration assays, $1 \times 10^{5}$ cells in $200 \mu \mathrm{l}$ of serum-free RPMI-1640 were placed in the upper chamber. Serum-free (600 $\mu \mathrm{l})$ RPMI-1640 containing various concentrations of CCL5 were placed in the lower chamber. Cells were incubated at $37^{\circ} \mathrm{C}$ for $12 \mathrm{~h}$. Then, cells on the upper surface of the filters were scraped with a cotton swab. Cells that had migrated and reached the lower surface of the filters were fixed in methanol, stained with H\&E and counted as previously described (24). In another set of migration assays, cells were pretreated for 30 min with different concentrations of maraviroc (Sigma). For invasion assays, the Transwell inserts were covered with Matrigel (BD Biosciences; $100 \mu \mathrm{g} / \mathrm{cm}^{2}$ ) and the cells were incubated on the inserts for $24 \mathrm{~h}$. The other steps were identical to those of the migration assays.

In vitro PNI assays. To study the effects of the CCR5/CCL5 axis on the PNI activity of SACC cells, we modified the in vitro PNI model established in our previous study (25). Briefly, the Transwell inserts were covered with Matrigel $\left(100 \mu \mathrm{g} / \mathrm{cm}^{2}\right)$. Cells $\left(1 \times 10^{5}\right)$ in $200 \mu$ l of serum-free RPMI-1640 were placed in the upper chamber. Then $600 \mu \mathrm{l}$ of conditioned medium (incubating $1 \times 10^{6}$ neural cells in $600 \mu 1$ serum-free RPMI1640 medium for $24 \mathrm{~h}$ ) was placed in the lower chamber to simulate the perineural surrounding environment. Cells were incubated at $37^{\circ} \mathrm{C}$ for $24 \mathrm{~h}$. Then, cells on the upper surface of the filters were removed. Cells that had invaded the Matrigel 


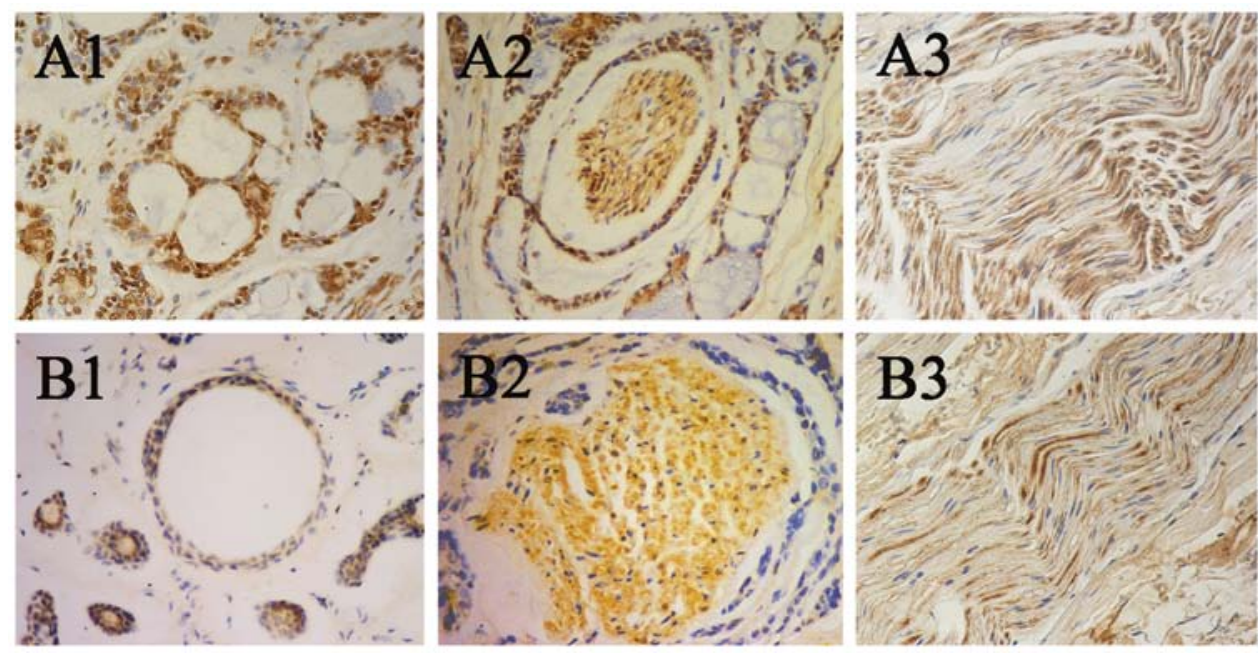

Figure 1. Immunohistochemical staining. (A1) Staining of CCR5 in primary SACC tissues (x400). CCR5 was highly expressed in the membrane and cytoplasm of tumor cells. (A2) Staining of CCR5 in a case of SACC with PNI (x400). CCR5 was highly expressed in the nerve tissues invaded by SACC. (A3) Staining of CCR5 in normal human peripheral nerve samples (x400). CCR5 was mainly expressed in the membrane and cytoplasm of neural cells. (B1) Staining of CCL5 in primary SACC tissues (x400). CCL5 was weakly expressed in the membrane and cytoplasm of tumor cells. (B2) Staining of CCL5 in the cases of SACC with PNI (x400). CCL5 was highly expressed in the nerve tissues invaded by SACC. (B3) Staining of CCL5 in normal human peripheral nerve samples (x400). CCL5 was mainly expressed in the membrane and cytoplasm of neural cells. SACC, salivary adenoid cystic carcinoma; PNI, perineural invasion.

Table I. Correlation between CCR5 and CCL5 expression and the perineural invasion of SACC.

\begin{tabular}{|c|c|c|c|c|c|c|c|c|c|}
\hline \multirow[b]{2}{*}{ Variables } & \multirow[b]{2}{*}{$\mathrm{n}$} & \multicolumn{3}{|c|}{ CCR5 } & \multirow[b]{2}{*}{ P-value } & \multicolumn{3}{|c|}{ CCL5 } & \multirow[b]{2}{*}{ P-value } \\
\hline & & - & + & ++ & & - & + & ++ & \\
\hline Perineural invasion & & & & & $0.027^{\mathrm{a}}$ & & & & 0.587 \\
\hline Positive & 34 & 6 & 10 & 18 & & 20 & 8 & 6 & \\
\hline Negative & 30 & 13 & 10 & 7 & & 21 & 6 & 3 & \\
\hline
\end{tabular}

${ }^{a} \mathrm{P}<0.05$ by Spearman's correlation test. SACC, salivary adenoid cystic carcinoma.

and reached the lower surface of the filters were fixed, stained and counted as previously described (25).

Statistical analysis. Statistical analysis was performed by SPSS 17.0 software package (USA). The differences in expression of CCR 5 and CCL5 were compared by the Fisher's exact test. Correlations were evaluated by the Spearman's rank correlation coefficient test. All in vitro assays were performed in triplicate, and the data are presented as means \pm SD. Results were analyzed with the Student's t-test and the one-way ANOVA tests. P-values $<0.05$ were considered to indicate statistically significant results in all tests.

\section{Results}

Expression of the CCR5/CCL5 axis in SACC. To determine the distribution of CCR5 and CCL5 in SACC and nerve tissues, we performed immunohistochemical analysis. The results showed that CCR5 was highly expressed in the cytoplasm and nuclei of the tumor cells and the neural cells (Fig. 1A1-A3). CCL5 was weakly expressed in the cytoplasm and the nuclei of the tumor cells, and was highly expressed in the cytoplasm and the nuclei of the neural cells (Fig. 1B1-B3). Notably, the expression of CCL5 in the nerve tissues with PNI was stronger than that in the normal nerve tissues (Fig. 1B2 and B3). Of the 64 SACC samples, CCR5 was detected in 45 cases (70.3\%), and CCL5 was observed in 23 cases (35.9\%). The statistical analysis showed that the expression of CCR5 was significantly corrrelated the PNI of SACC $(\mathrm{P}<0.05$; Table I), while the expression of CCL5 was negatively associated with the PNI of SACC $(\mathrm{P}>0.05$; Table I).

To examine the expression of CCR5 and CCL5 in SACC-83 cells, flow cytometric analysis and immunofluorescence analysis were performed. As shown in Fig. 2A1 and A2, flow cytometric analysis showed that SACC-83 cells highly expressed CCR5 and weakly expressed CCL5. In addition, immunofluorescence analysis also demonstrated the stronger expression of CCR5 and weaker expression of CCL5 in SACC-83 cells (Fig. 2B1 and B2).

Effect of CCL5/CCR5 on calcium influx and F-actin polymerization of SACC-83 cells. To verify that the CCL5/CCR5 axis was functional, the cytoplasmic free $\mathrm{Ca}^{2+}$ concentration was measured by flow cytometric analysis. Fig. 3A shows a rapid and transient $\mathrm{Ca}^{2+}$ elevation in SACC-83 cells preloaded with Fluo-3AM after the addition of CCL5. However, $\mathrm{Ca}^{2+}$ 

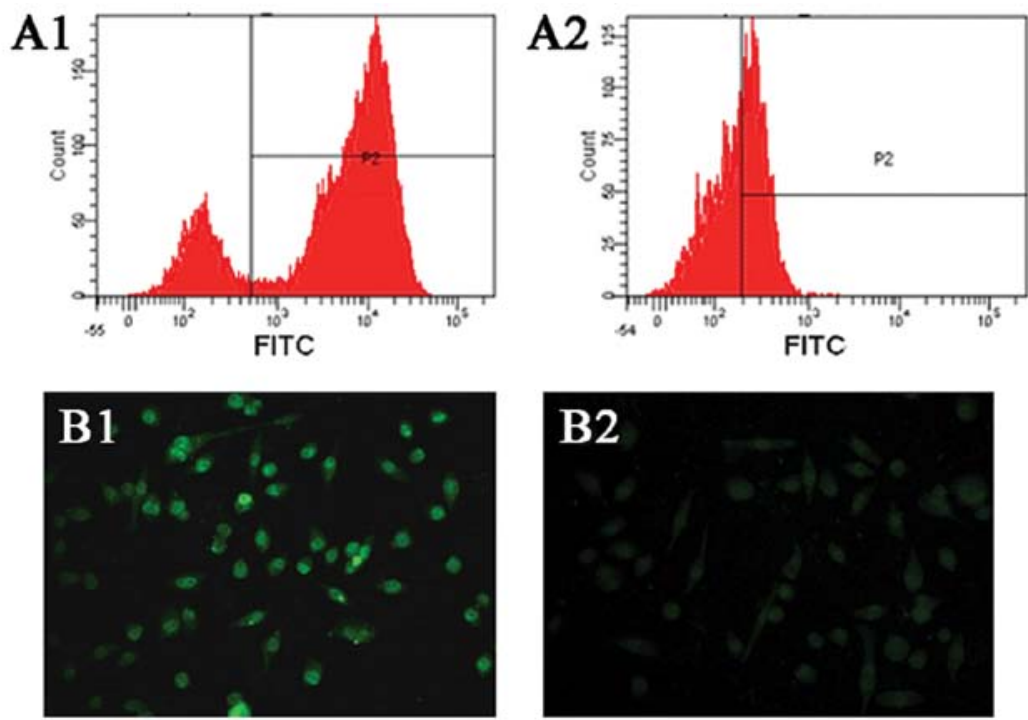

Figure 2. Expression of CCR5 and CCL5 in SACC-83 cells. (A1) Flow cytometry showed that CCR5 was positively expressed in SACC-83 cells (73.3\%). (A2) Flow cytometry showed that CCL5 was weakly expressed in SACC-83 cells (20.8\%). (B1) Immunofluorescence staining showed that CCR5 was highly expressed in SACC-83 cells. (B2) Immunofluorescence staining showed that CCL5 was weakly expressed in SACC-83 cells. SACC, salivary adenoid cystic carcinoma.
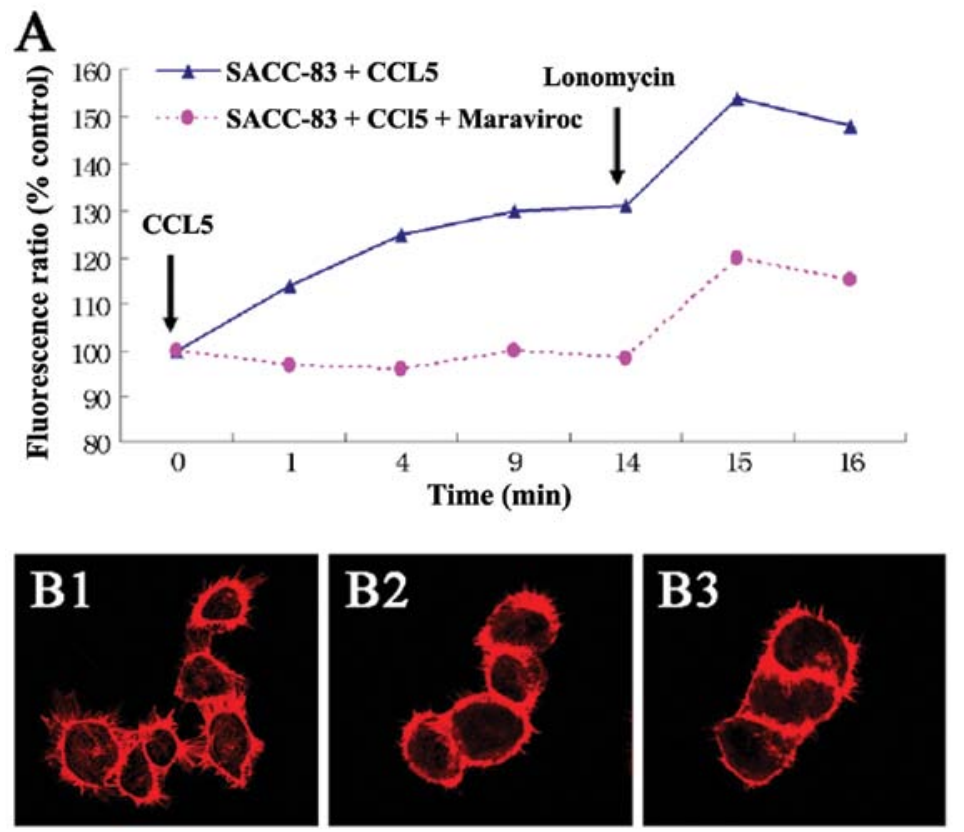

Figure 3. $\mathrm{Ca}^{2+}$ mobilization and actin polymerization assays. (A) $\mathrm{Ca}^{2+}$ mobilization assays. The interaction between CCL5 and CCR5 induced a rapid $\mathrm{C}^{2+}$ elevation in SACC-83 cells. CCR5 inhibitor, maraviroc, inhibited $\mathrm{Ca}^{2+}$ elevation under the condition of CCL5 stimulation. To induce maximal Ca ${ }^{2+}$ release, cells were subsequently stimulated with lonomycin. These results confirmed that CCR5 expression in SACC-83 cells was a functional receptor that may respond to its ligand CCL5. Actin polymerization assays: (B1) F-actin polymerization induced by $100 \mathrm{ng} / \mathrm{ml}$ exogenous CCL5 was observed by confocal microscopy (x600). Intense F-actin staining in the periphery of the cells and distinct pseudopodium formation were observed following stimulation with CCL5. However, these changes were not observed in the negative group (B2) or in the CCR5 inhibitor group (B3). SACC, salivary adenoid cystic carcinoma.

fluctuation in SACC-83 cells pretreated with $200 \mathrm{ng} / \mathrm{ml}$ maraviroc (CCR5 inhibitor) was not obviously changed after the addition of CCL5.

To investigate whether F-actin polymerization is induced by the CCL5/CCR5 axis in SACC-83 cells, we observed changes in F-actin in SACC-83 cells by confocal microscopy. As a result, after treatment with CCL5 at $100 \mathrm{ng} / \mathrm{ml}$ for $30 \mathrm{~min}, \mathrm{SACC}-83$ cells showed intense F-actin staining in the periphery of the cells and distinct pseudopodium formation (Fig. 3B1). However, the cells in the control group or the cells pre-blocked for CCR5 by $200 \mathrm{ng} / \mathrm{ml}$ maraviroc showed no marked F-actin redistribution and pseudopodium formation (Fig. 3B2 and B3).

Effects of the CCR5/CCL5 axis on the migration and invasion of SACC-83 cells. To assess the effects of the CCL5/CCR5 

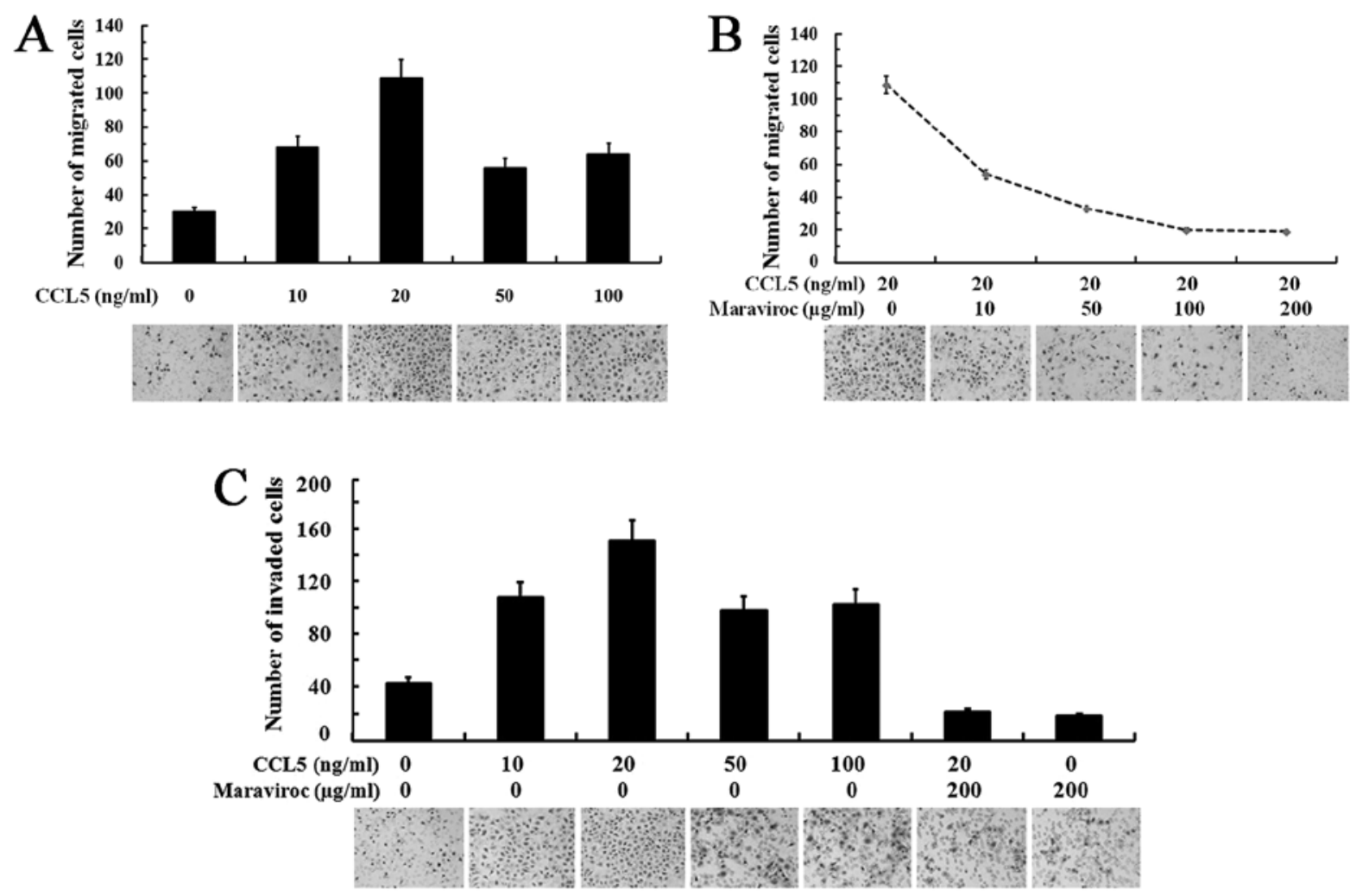

Figure 4. Migration and invasion assays. (A) Migration assays. Exogenous CCL5 stimulated the migration of SACC-83 cells in a dose-dependent manner, and maximal effect was observed at $20 \mathrm{ng} / \mathrm{ml}$ of CCL5 (P<0.05). (B) Effect of the CCR5 inhibitor on migration. The CCL5-stimulated migration of SACC-83 cells was inhibited by the CCR5 inhibitor maraviroc. A maximal effect was observed at 100-200 ng/ml maraviroc (P<0.05). (C) Effect of the CCL5/CCR5 axis on the invasive activity of SACC- 83 cells. SACC- 83 cells were stimulated by various concentrations of CCL5 and a maximal effect was observed at $20 \mathrm{ng} /$ $\mathrm{ml}$. In addition, the CCL5-stimulated invasion was effectively inhibited by the CCR5 inhibitor maraviroc at $200 \mu \mathrm{g} / \mathrm{ml}(\mathrm{P}<0.05)$. Data are expressed as the mean number of migrated cells/well, and each experiment was repeated 3 times. Columns, mean of 3 separate experiments in triplicate wells. SACC, salivary adenoid cystic carcinoma.

axis on the migration and invasion activities of SACC-83 cells, we performed Transwell assays under the condition of CCL5 stimulation and/or CCR5 blockage. Fig. 4A shows that various concentrations of CCL5 promoted the migration of SACC-83 cells. A Maximal promotive effect of CCL5 on the migration of SACC-83 cells was observed at a concentration of $20 \mathrm{ng} / \mathrm{ml}(\mathrm{P}<0.05)$. In addition, the migration of SACC-83 cells induced by CCL5 at $20 \mathrm{ng} / \mathrm{ml}$ was maximally inhibited by maraviroc at concentrations from 100 to $200 \mu \mathrm{g} / \mathrm{ml}$ ( $\mathrm{P}<0.05$; Fig. 4B).

The effects of CCL5 and the CCR5 inhibitor on the invasive activity of SACC- 83 cells are shown in Fig. 4C. CCL5 $(20 \mathrm{ng} / \mathrm{ml})$ obviously promoted the invasion of SACC-83 cells $(\mathrm{P}<0.05)$, while $200 \mu \mathrm{g} / \mathrm{ml}$ maraviroc significantly inhibited the CCL5-induced invasiveness of SACC-83 cells $(\mathrm{P}<0.05)$. In addition, SACC- 83 cells pretreated by maraviroc showed no significantly changes in invasion activity when stimulated with $20 \mathrm{ng} / \mathrm{ml}$ CCL5 or without ( $>0.05)$.

Effects of the CCL5/CCR5 axis on the PNI activity of SACC-83 cells. The effects of the CCR5/CCL5 axis on the PNI activity of SACC cells were studied by modified in vitro PNI models. As shown in Fig. 5, after $24 \mathrm{~h}$ of incubation, abundant SACC-83 cells were observed on the lower surface of the filter when the lower chamber was supplemented with neural cell conditioned medium to simulate the perineural surrounding environment.

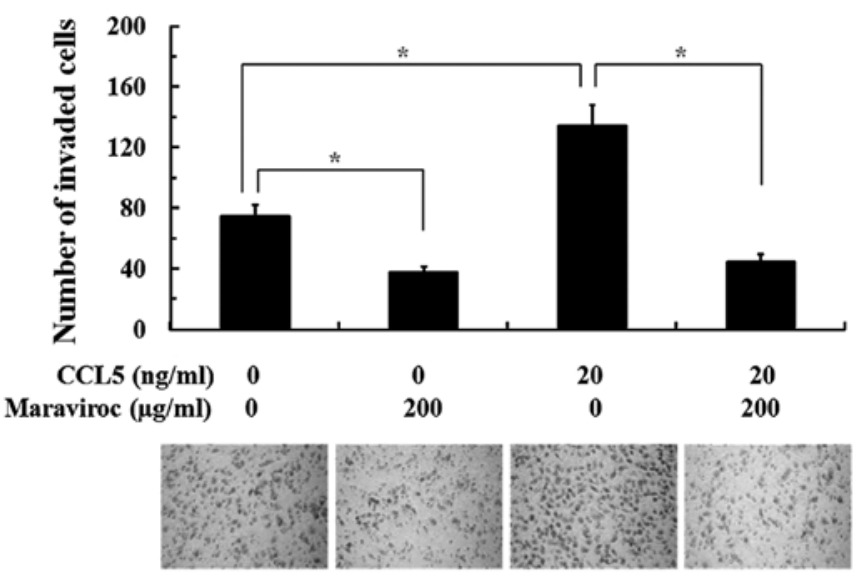

Figure 5. Effects of the CCR5/CCL5 axis on the PNI activity of SACC cells were studied using a modified in vitro PNI model. After $24 \mathrm{~h}$ of incubation, abundant SACC- 83 cells were observed on the lower surface of the filter. The PNI activity of SACC- 83 cells was significantly increased under a condition of $20 \mathrm{ng} / \mathrm{ml}$ CCL5 when compared with the control group $\left({ }^{*} \mathrm{P}<0.05\right)$. Compared with the control group, the PNI activity of SACC-83 cells both with or without CCL5 stimulation was obviously inhibited when cells were pretreated with $200 \mu \mathrm{g} / \mathrm{ml}$ maraviroc $\left({ }^{*} \mathrm{P}<0.05\right)$. PNI, perineural invasion; SACC, salivary adenoid cystic carcinoma.

The PNI activity of SACC- 83 cells was significantly increased under the condition of $20 \mathrm{ng} / \mathrm{ml}$ CCL5 when compared with 
the control group $(\mathrm{P}<0.05)$. Compared with the control group, the PNI activity of SACC-83 cells both with or without CCL5 stimulation was obviously inhibited when cells were pretreated with $200 \mu \mathrm{g} / \mathrm{ml}$ maraviroc $(\mathrm{P}<0.05)$.

\section{Discussion}

Salivary adenoid cystic carcinoma (SACC) has a special proclivity for perineural invasion (PNI), which leads to tumor recurrence and poor prognosis $(2,3,21)$. Elucidation of the molecules involved in the progression of PNI would provide new insight for the understanding of the mechanisms of PNI and would be beneficial for the control of SACC with PNI. Recent studies have shown that the chemokine CCL5 and its receptor CCR5 play important roles in tumor invasion and metastasis (14-19). However, the role of the CCL5/CCR5 axis in the PNI of SACC has not been studied to date. In the present study, we found that SACC tissues and cells highly expressed CCR5, while the nerves invaded by SACC expressed elevated levels of CCL5. Immunohistochemical analysis showed that high expression of CCR5 was significantly associated with the PNI of SACC. In the in vitro assays, we found that exogenous CCL5 significantly promoted the migration, invasion and PNI activity of SACC-83 cells, while the CCR5 inhibitor effectively inhibited the migration, invasion and PNI activity of SACC-83 cells both with or without CCL5 stimulation. These findings suggest that the CCL5/CCR5 axis may contribute to the progression of PNI of SACC.

To verify whether the interaction of CCR5 and its ligand was functional, we detected the cytoplasmic free $\mathrm{Ca}^{2+}$ concentration and the reorganization of actin cytoskeleton after stimulation with CCL5. Numerous studies have shown that a rapid and transient $\mathrm{Ca}^{2+}$ elevation was induced by chemokine in a series of tumors and was significantly correlated with the mobility of tumor cells $(19,23)$. Our results showed an obvious $\mathrm{Ca}^{2+}$ elevation after stimulation by CCL5 in SACC-83 cells. We also found that SACC-83 cells pretreated with the CCR5 inhibitor showed no marked intracellular calcium flow both with or without CCL5 stimulation. In tumor cells, high levels of actin polymerization are needed for the formation of pseudopodia, which is the foundation and early event of efficient migration and invasion of tumor cells $(26,27)$. Invading cells require an alteration in the cell-cell adhesion properties and reorganize their cytoskeletons to facilitate cell motility $(26,27)$. In the present study, we observed that, following treatment of SACC-83 cells with CCL5, marked actin polymerization and pseudopodium formation were noted in the periphery of cells. These results indicate that the CCR5 expressed in SACC cells was the functional receptor that responds to CCL5. Take together, the motility of SACC cells may be associated with the cytoplasmic free $\mathrm{Ca}^{2+}$ concentration and the reorganization of actin cytoskeleton induced by CCL5/CCR5 axis activation.

During the process of invasion, invading cells require a change in cell-cell adhesion properties, reorganization of their cytoskeleton and reconstitution of the extracellular microenvironment (28). To confirm the functionality of the CCL5/CCR5 axis in SACC cell migratory and invasive activity, we evaluated the migration and invasion capabilities of SACC cells by adding CCL5 or by blocking CCR5 in vitro. We found that exogenous
CCL5 facilitated the migration and invasion of SACC cells. We also found that neutralizing CCR5 by the CCR5 inhibitor efficiently impaired the migration and invasion of SACC cells. In addition, we found that the CCL5/CCR5 axis was associated with the PNI of SACC cells in vitro. The PNI ability of SACC cells was improved after adding exogenous CCL5, and was obviously suppressed by the CCR5 inhibitor. These results indicate that the CCL5/CCR5 axis plays a critical role in the migration, invasion and PNI activity of SACC cells.

Traditionally, studies of PNI have focused on the neurotropism of tumor cells. Whereas recent findings underline the interaction of tropism between tumor and nerve cells, nerve tissues provide a prosperous microenvironment for tumor invasion and this interaction has beneficial effects on the growth and motility of both tumor and nerve cells $(1,20)$. One study previously found that obvious reciprocity between neurite outgrowth from mouse dorsal root ganglia (DRG) and pancreatic cancer ( $\mathrm{PCa}$ ) cell invasive growth was observed when human PCa cells were co-cultured with mouse DRG (29). Swanson et al also discovered tumor-nerve interactions by means of the transmembrane mucin MUC1 expressed by tumor cells binding to myelin-associated glycoprotein expressed on Schwann cells of peripheral nerves (30). In the present study, we observed the role of the CCL5/CCR5 axis in the PNI of SACC cells. We found that CCR5 was highly expressed in SACC cells, while CCL5 was obviously observed in nerves invaded by SACC. Moreover, exogenous CCL5 functionally activated the CCR5 and thus promoted the motility and PNI activity of SACC cells in vitro. The CCR5 inhibitor significantly inhibited the motility and PNI activity of SACC cells. All of these results suggest that the activation of the CCR5/CCL5 axis may be a potent mechanism for the PNI of SACC. However, whether the CCL5/CCR5 axis is involved in the reciprocal growth interaction between nerves and SACC in the progression of PNI needs to be further explored.

The tumor-nerve interaction is an important research topic, and not only their abundant resounding potential, but also the major therapeutic potential deserves considerable attention. Maraviroc is a new CCR5 antagonist (31). It has received full US Food and Drug Administration (FDA) approval for use in treatment-naive adults with CCR5-trophic HIV (32). Recent studies have shown that maraviroc inhibits breast cancer cell invasion in vitro and effectively reduces migration of breast cancer cells to target organs in vivo (19). Therefore, maraviroc is considered to be an antineoplastic agent for breast tumors and other tumor types that highly express CCR5 $(9,19)$. Our study found that exogenous CCL5 promoted the in vitro PNI activity of SACC cells that highly express CCR5. Our study further found that maraviroc effectively inhibited the PNI activity of SACC cells. These results suggest that maraviroc may interrupt the tumor-nerve interaction through blocking activation of the CCL5/CCR5 axis and thus may inhibit the PNI progression of SACC cells.

In conclusion, this is the first study to show that the CCL5/CCR5 axis acts as a crucial mediator of the PNI of SACC. Moreover, the CCR5 inhibitor maraviroc may effectively suppress the PNI activity of SACC cells in vitro. Our study suggests that small-molecule antagonists of CCR5 may be a potent anti-PNI agent for SACC. 


\section{Acknowledgements}

We thank Professor Zhou Jun and Dr Liu Yuan for their excellent technical assistance. This work was supported by the National Natural Science Foundation of China for Dr Moyi Sun (grant nos. 81072230, 30772428) and Dr Xinjie Yang (grant no. 81302352).

\section{References}

1. Liebig C, Ayala G, Wilks JA, Berger DH and Albo D: Perineural invasion in cancer: a review of the literature. Cancer 115 3379-3391, 2009

2. Barrett AW and Speight PM: Perineural invasion in adenoid cystic carcinoma of the salivary glands: a valid prognostic indicator? Oral Oncol 45: 936-940, 2009.

3. Johnston M, Yu E and Kim J: Perineural invasion and spread in head and neck cancer. Expert Rev Anticancer Ther 12: 359-371, 2012.

4. Poeschl EM, Pollheimer MJ, Kornprat P, et al: Perineural invasion: correlation with aggressive phenotype and independent prognostic variable in both colon and rectum cancer. J Clin Oncol 28: e358-e360, 2010.

5. Fromont G, Godet J, Pires C, Yacoub M, Dore B and Irani J: Biological significance of perineural invasion $(\mathrm{PNI})$ in prostate cancer. Prostate 72: 542-548, 2012.

6. Sakurai J, Fujii Y and Shirotani M: Contraction induced by Clostridium perfringens alpha toxin in the isolated rat ileum. Toxicon 28: 411-418, 1990.

7. Cavel O, Shomron O, Shabtay A, et al: Endoneurial macrophages induce perineural invasion of pancreatic cancer cells by secretion of GDNF and activation of RET tyrosine kinase receptor. Cancer Res 72: 5733-5743, 2012.

8. Bapat AA, Hostetter G, von Hoff DD and Han H: Perineural invasion and associated pain in pancreatic cancer. Nat Rev Cancer 11: 695-707, 2011

9. Wang SW, Wu HH, Liu SC, et al: CCL5 and CCR5 interaction promotes cell motility in human osteosarcoma. PLoS One 7: e35101, 2012.

10. McIver SC, Loveland KL, Roman SD, Nixon B, Kitazawa R and McLaughlin EA: The chemokine CXCL12 and its receptor CXCR4 are implicated in human seminoma metastasis. Andrology 1: 517-529, 2013.

11. Zhu Q, Han X, Peng J, Qin H and Wang Y: The role of CXC chemokines and their receptors in the progression and treatment of tumors. J Mol Histol 43: 699-713, 2012.

12. Lv D, Zhang Y, Kim HJ, Zhang L and Ma X: CCL5 as a potential immunotherapeutic target in triple-negative breast cancer. Cell Mol Immunol 10: 303-310, 2013.

13. Bolin LM, Murray R, Lukacs NW, et al: Primary sensory neurons migrate in response to the chemokine RANTES. J Neuroimmunol 81: 49-57, 1998.

14. Vaday GG, Peehl DM, Kadam PA and Lawrence DM: Expression of CCL5 (RANTES) and CCR5 in prostate cancer. Prostate 66: 124-134, 2006.

15. Borczuk AC, Papanikolaou N, Toonkel RL, et al: Lung adenocarcinoma invasion in TGF $\beta R I I$-deficient cells is mediated by CCL5/RANTES. Oncogene 27: 557-564, 2008.
16. Zhang Y, Yao F, Yao X, et al: Role of CCL5 in invasion, proliferation and proportion of CD44+/CD24- phenotype of MCF-7 cells and correlation of CCL5 and CCR5 expression with breast cancer progression. Oncol Rep 21: 1113-1121, 2009.

17. Swamydas M, Ricci K, Rego SL and Dréau D: Mesenchymal stem cell-derived CCL-9 and CCL-5 promote mammary tumor cell invasion and the activation of matrix metalloproteinases. Cell Adh Migr 7: 315-324, 2013.

18. Pinilla S, Alt E, Abdul Khalek FJ, et al: Tissue resident stem cells produce CCL5 under the influence of cancer cells and thereby promote breast cancer cell invasion. Cancer Lett 284: 80-85, 2009.

19. Velasco-Velázquez M, Jiao X, De La Fuente M, et al: CCR5 antagonist blocks metastasis of basal breast cancer cells. Cancer Res 72: 3839-3850, 2012.

20. Demir IE, Friess H and Ceyhan GO: Nerve-cancer interactions in the stromal biology of pancreatic cancer. Front Physiol 3: 97, 2012.

21. Li LJ, Li Y, Wen YM, Liu H and Zhao HW: Clinical analysis of salivary gland tumor cases in West China in past 50 years. Oral Oncol 44: 187-192, 2008.

22. Yang X, Dai J, Li T, et al: Expression of EMMPRIN in adenoid cystic carcinoma of salivary glands: correlation with tumor progression and patients' prognosis. Oral Oncol 46: 755-760, 2010.

23. Sukhanova KY, Harhun MI, Bouryi VA and Gordienko DV: Mechanisms of $[\mathrm{Ca} 2+]$ i elevation following $\mathrm{P} 2 \mathrm{X}$ receptor activation in the guinea-pig small mesenteric artery myocytes. Pharmacol Rep 65: 152-163, 2013.

24. Yang X, Zhang P, Ma Q, et al: EMMPRIN contributes to the in vitro invasion of human salivary adenoid cystic carcinoma cells. Oncol Rep 27: 1123-1127, 2012.

25. Yang X, Zhang $\mathrm{P}, \mathrm{Ma} \mathrm{Q}$, et al: EMMPRIN silencing inhibits proliferation and perineural invasion of human salivary adenoid cystic carcinoma cells in vitro and in vivo. Cancer Biol Ther 13: 85-91, 2012.

26. Bravo-Cordero JJ, Hodgson L and Condeelis J: Directed cell invasion and migration during metastasis. Curr Opin Cell Biol 24: 277-283, 2012.

27. Olson MF and Sahai E: The actin cytoskeleton in cancer cell motility. Clin Exp Metastasis 26: 273-287, 2009.

28. Detchokul S, Williams ED, Parker MW and Frauman AG: Tetraspanins as regulators of the tumourmicroenvironment: implications for metastasis and therapeutic strategies. Br J Pharmacol: Jun 3, 2013 (Epub ahead of print). doi: 10.1111/bph.12260.

29. Dai H, Li R, Wheeler T, Ozen M, et al: Enhanced survival in perineural invasion of pancreatic cancer: an in vitro approach. Hum Pathol 38: 299-307, 2007.

30. Swanson BJ, McDermott KM, Singh PK, Eggers JP, Crocker PR, and Hollingsworth MA: MUC1 is a counter-receptor for myelin-associated glycoprotein (Siglec-4a) and their interaction contributes to adhesion in pancreatic cancer perineural invasion. Cancer Res 67: 10222-10229, 2007.

31. Sayana S and Khanlou H: Maraviroc: a new CCR5 antagonist. Expert Rev Anti Infect Ther 7: 9-19, 2009.

32. Kast RE: Glioblastoma: synergy of growth promotion between CCL5 and NK-1R can be thwarted by blocking CCL5 with miraviroc, an FDA approved anti-HIV drug and blocking NK-1R with aprepitant, an FDA approved anti-nausea drug. J Clin Pharm Ther 35: 657-663, 2010. 